\title{
Vocabulary Knowledge and Learning Strategies of Senior High School Students
}

\author{
Jennifer P. Santillan ${ }^{1, *}$, Richard G. Daenos ${ }^{2}$ \\ ${ }^{1}$ College of Education, Graduate School and Office of the Vice President for Academic Affairs, Angeles University Foundation, \\ Philippines \\ ${ }^{2}$ Institute of Education, Arts and Sciences, City College of Angeles, Philippines
}

Received March 17, 2020; Revised April 27, 2020; Accepted May 20, 2020

Copyright $(2020$ by authors, all rights reserved. Authors agree that this article remains permanently open access under the terms of the Creative Commons Attribution License 4.0 International License

\begin{abstract}
Vocabulary knowledge is crucial in the understanding of a material and in the development of the macro-skills, most especially reading. When reading, a person may overestimate or underestimate his/ her vocabulary knowledge, thinking that she/ he knows the meaning of words in the text. Also, to repair the lack of knowledge of a word in the text and to ensure comprehension, she/ he may use vocabulary-learning strategies (VLS). This basic qualitative study aimed to identify and compare the presumed vocabulary knowledge and actual vocabulary knowledge and the VLS of grade 12 students of Angeles City, Philippines. To answer research questions, the researchers used an expository reading text, a semi-structured interview guide, and a researcher-made vocabulary test as instruments. They also utilized descriptive statistics and inductive and thematic analysis of qualitative data. Findings of this study reveal that the participants' presumed vocabulary knowledge ranges from $57 \%$ to $97 \%$ of the self-reported unfamiliar words while their actual vocabulary knowledge ranges from $50 \%$ to $91 \%$, which presumed vocabulary knowledge is higher than actual vocabulary knowledge, and that participants use eight VLS classified into themes. These results imply the need to enhance the curriculum, specifically on vocabulary, to facilitate learning of strategies and to provide more practice of the VLS through reading.
\end{abstract}

$\begin{array}{lcc}\text { Keywords } & \text { Vocabulary } & \text { Knowledge, } \\ \text { Vocabulary-learning Strategies, Vocabulary Learning }\end{array}$

\section{Introduction}

Vocabulary refers to the depth and breadth of words that people use, recognize, and respond to and is essential in communication. While comprehension and communication are possible with incorrect grammar, they are far fetched without vocabulary. That is why developing knowledge on vocabulary is a lifelong process and is of life-like importance [1].

Moreover, vocabulary is necessary in the development of all the macro skills which are speaking, reading, writing, and listening. People need rich vocabulary to grasp messages encountered in text and in conversations. They also need an extensive expressive vocabulary to write essays and researches and do oral presentations anywhere [2].

Specifically, vocabulary is one of the core components that reading comprehension has $[1,3,4,5]$. Reading comprehension pertains to a "meeting of the minds" of an author and a reader; it is present when readers' mental representations of what they have read match the conceptual relations intended by authors. To comprehend, a reader must understand what the words in the text mean since word meaning makes up 70 to $80 \%$ of comprehension [6].

Meanwhile, vocabulary size is even predictive of later reading achievement [4] and overall academic performance [6]. Because students are likely to encounter 100,000 words, which are usually unknown [5], those with strong vocabulary tend to find reading easy and they also build their vocabulary as they read [4].

Despite its importance, vocabulary acquisition remains as one of the most difficult skills to teach and to learn. This difficulty may be rooted from poor schemata. According to the Schema Theory, students with restricted prior knowledge have more trouble learning new words [2]. They may also experience the Matthew Effect [4]; that is, students who do not really read well do not read, thus having deficit vocabulary building opportunities.

In the Philippines, the knowledge on vocabulary is 
salient especially for junior and senior high school learners for them to meet the competencies required by the Department of Education (DepEd) and to survive other reading demands which are usually academic [8]. Among the senior high school subjects requiring much reading and vocabulary knowledge are Practical Research 1 and 2 and English for Academic and Professional Purposes. The same subjects target competencies which are pre-requisite in tertiary education. However, not everyone in the higher grades is ready for the requirements. Some reasons behind poor vocabulary include poverty and lack of exposure to meaningful conversations, vocabulary instruction, and poor reading [9]. As a result of poor vocabulary, students encounter difficulty with fluency [5], with standardized tests [4] and with reading in general $[4,6]$.

To address concerns on vocabulary learning, readers can employ a variety of vocabulary-learning strategies (VLS) [10-13]. VLS may involve preferences and procedures, entail knowledge, and improve effectiveness in vocabulary learning. By teaching VLS, teachers help students to reach a level of vocabulary autonomy and later independence [15]. After discussions on VLS, students need much time in expanding vocabulary and learning word analysis skills, which are the building blocks of advanced literacy, in their language courses [16].

Because the K-12 curriculum was new, and it has not produced grade 12 completers during the time of the study, the researchers wanted to know if students in grade 12 possessed the expected vocabulary knowledge and knew and practiced the VLS which are in their language curriculum.

This research, therefore, aimed to identify and compare the presumed vocabulary knowledge and actual vocabulary knowledge and identify the actual vocabulary-learning strategies of grade 12 students.

\section{Materials and Methods}

This paper is a basic qualitative research. The participants in this paper were six grade 12 students from the first batch of senior high school learners in the Philippines, particularly in the school year 2017 to 2018 . They were chosen using purposive sampling, lottery method and snowball sampling techniques. They are L2 learners of English and regular learners without special needs. They met the criteria with basic vocabulary skills [8] and in grade 12 because the year level includes lessons on vocabulary and VLS. The schools were picked using lottery method; three were public schools while the other three were private schools. In the Philippines, both public and private schools target at least the minimum competencies set by the DepEd. Private schools usually have an advantage in terms of facilities and available technology; they too most often enrich the curriculum by using appropriate technology and even designing a special curriculum just like what two of the schools involved in this research did. All respondents were referred by the school heads or English teachers who agreed for their school to be included as locale. Participants signed informed consent form while the participant who was then under 18 years old had her parent sign the consent as well. All of whom are identified in this study by pseudonyms.

The researchers used an article titled Digital Realism [17] which they took from a local newspaper as reading text. The choice of expository text was influenced by the exposure of the learners to this text type. The researchers also used a semi-structured interview guide which centered on the words the participants considered difficult and their VLS. Also, they utilized a 30-item researcher-made, multiple-choice vocabulary test based on the model of Christ, Chiu, Currie and Cipielewski [18]. The words in the test were lifted from the reading text and considered unfamiliar to learners [19] as determined by three English teacher-informants. All four informants have been teaching English for at least 10 years and with at least master's degree in English; two were teachers in grade 12 in two of the locales, one was a schools-division superintendent, and one has strong background on language assessment.

Using validation tools, the same informants validated the reading text and the multiple-choice test in which words were presented in isolation with four plausible options on the meaning of the given words. The researchers opted not to use the words in sentences to allow participants to use any VLS and underlined the same words in the reading text. A sample item is below.

\section{Lavish}
a. simple
b. impoverished
c. extravagant
d. moderate

During the data collection, each participant read silently the article, answered interview questions right after, then answered the test. While answering the test, they could refer to the text and easily find the underlined target words. Easily locating the words allowed them to apply their VLS.

The researchers audio recorded the interview and transcribed it manually. They analyzed data, coded them, and formed themes. Themes were created using conventional and inductive approaches as defined by Hsieh and Shannon [20] and Thomas [21]. All participants did member checking of the transcript and the analysis of the researchers.

\section{Results}

When asked what words they considered difficult, participants overestimated their vocabulary knowledge by naming fewer words as compared with the words they failed to answer correctly. Although the participants could 
name any word in the text as difficult, they named the underlined words or those in the vocabulary test.

In particular, Jake identified one unfamiliar word (subliminally) but missed three (curating, fancy, and precipitated). Ervin named metanoia and musings as unknown but got four words (absurdity, curating, precipitated, and tedious) incorrectly; he did not consider those four words unfamiliar at first.

For clarity, the researchers underlined the terms the participants considered highfalutin and missed during the test. Ivy named 13 words (advocacy, aerial, ballistic, curating, deranged, lavish, metanoia, musings, persona, precipitated, scorched, subliminally, and tedious) but got 15 terms (absurdity, aerial, ballistic, candid, deranged, fancy, flawed, junkies, lavish, metanoia, musings, precipitated, tedious, vanity, and virtual) which were incorrect responses; she, however, missed answering eight out of the 13 words she considered new to her.

Bessy, on the other hand, mentioned two (metanoia and musings) but actually missed six words (absurdity, ballistic, curating, flawed, musings, and precipitated); she failed to answer just one of the two terms she identified as unknown prior to the test. Anna seemingly predicted the turnout of her test (20\% errors) as she picked six words (curating, deranged, junkies, musings, subliminally, and tedious) in the text, which were unfamiliar to her. Although she got six incorrect answers (absurdity, aerial, ballistic, curating, flawed, and vanity), she got a cross mark in five words which she inferred were familiar. Fatima uttered that she did not know curating and metanoia, but she incurred four wrong answers (advocacy, curating, vanity, and vibe); one of them was truly unknown to her.

Table 1 details the perceived and actual vocabulary knowledge of the participants. Percentages were computed by dividing the number of perceived difficult word or number of words incorrectly defined in the test by 30 or the total number of unfamiliar words in the text.

Table 1. Vocabulary knowledge as perceived and computed

\begin{tabular}{|c|c|c|}
\hline Participant & Perceived & Actual \\
\hline Jake & $97 \%$ & $91 \%$ \\
\hline Ervin & $93 \%$ & $87 \%$ \\
\hline Ivy & $57 \%$ & $50 \%$ \\
\hline Bessy & $93 \%$ & $80 \%$ \\
\hline Anna & $80 \%$ & $80 \%$ \\
\hline Fatima & $93 \%$ & $87 \%$ \\
\hline
\end{tabular}

The themes that emerged from the interview were (a) Re-reading as umbrella VLS, (b) Using context clues in the same sentence and paragraph, (c) Using the dictionary, (d) Surfing the internet as the convenient choice, (e) Associating with familiar words and experiences, (f) Analyzing word structure, (g) Asking "reliable" sources, and (h) Reading as habit. The table below summarizes the number of respondents who chose these VLS.

Table 2. VLS of respondents

\begin{tabular}{|c|c|}
\hline VLS & Frequency \\
\hline $\begin{array}{c}\text { Re-reading as umbrella VLS } \\
\text { Using context clues in the same sentence and } \\
\text { paragraph }\end{array}$ & 6 \\
\hline Using the dictionary & 4 \\
\hline Surfing the internet as the convenient choice & 2 \\
\hline Associating with familiar words and experiences & 2 \\
\hline Analyzing word structure & 2 \\
\hline Asking "reliable" sources & 1 \\
\hline Reading as habit & 1 \\
\hline
\end{tabular}

\section{Discussion}

Overestimation of vocabulary knowledge was also evident in the study of Shen [40] but the cited study is in an EFL context. Shen noted that participants mistakenly thought they knew the meaning of words with polysemy or multiple definitions. Possible overestimation in the current study can be traced from understanding the central message of the text especially because its topic is taking pictures for social media account. Readers tend to disregard some words in text as long as they comprehend content.

The most unfamiliar words based on participants' perception alone were metanoia and musings ( $\mathrm{n}=5$ or $83 \%$ of the participants). Only Jake did not mention them as unfamiliar words. According to the test, curating is the most unfamiliar ( $\mathrm{n}=5$ or $83 \%$ ); absurdity and precipitated $(n=4)$, and ballistic, flawed, and vanity $(n=3$ or $59 \%)$ come next. With perception and test results combined, curating is the most unfamiliar word. Three perceived it as a difficult word and five missed selecting its correct meaning in the test. Curating is followed by musings and precipitated and absurdity, ballistic, and tedious.

The following are the participants' VLS presented as themes.

\section{$\underline{\text { Re-reading as umbrella VLS }}$}

All the respondents used re-reading as a strategy to know the meaning of unfamiliar words. Fatima read sentences with her perceived difficult words thrice while the rest, she read twice. Ivy said that her re-reading was done intently or seriously.

In Fatima's sharing, one could infer that she also advocates re-reading not just for vocabulary but for comprehension. If a reader does not know the words in the text, then she/he would also find understanding the text problematic [6]. Fatima's claim also supports the idea of multiple exposures to an unknown word [e.g., 23,24]. This exposure must be in different occasions and modes. 
In addition, re-reading allows a person to understand a sentence better by paraphrasing [25] and by finding a clue in the sentence where the unfamiliar word appears. This finding agrees with those of Snell, Hindman, and Wasik [26] who learned that re-reading helps improve vocabulary though their respondents were pre-elementary learners. These readers read again the entire material, not only the sentences with unfamiliar terms.

This strategy of all six respondents is considered a self-learning strategy [2]. It is something one can do on his/her own. It, however, requires the admission among readers that they do not know a word.

Also, the respondents did not ignore the unknown word [2]. The move to know the meaning of a word before continuing reading means the word is crucial to understand the entire text. Instead of ignoring a word, the participants did metacognition particularly monitoring their understanding which led them to pinpoint a difficult word and exert effort to understand it [27].

Though the set time for reading was 15 minutes, the participants were not time pressured. No participant exceeded the time limit though all of them turned back to some pages previously read perhaps to re-read while answering the test.

Re-reading as VLS is an evidence of strong general vocabulary. A person re-reads knowing that in doing so, she/he can decipher the meaning of words through clues, structural analysis, association, among others. Without firm general vocabulary required in finding clues, structural analysis, and association, one cannot find word meaning despite reading again.

It is notable as well that re-reading is an umbrella strategy which enabled respondents to find clues in the same sentence and even associate the unfamiliar vocabulary with other words in the sentence. However, these other subsumed strategies are discussed separately in this paper. It is therefore safe to say that the participants' VLS are eclectic or a combination of re-reading and another.

\section{Using context clues in the same sentence and paragraph}

All five respondents, except Ivy, employed the use of context clues to know the meaning of self- perceived difficult words. Jake, Ervin, Anna, and Fatima got hints from the other words in the sentence also by re-reading.

The use of context clues is a recognized technique $[1,5,14,28,29]$. Although Fatima searches for clues out of her self-proclaimed laziness, she does not realize that this strategy is demanding. It requires her to read again and to know the meaning of other words possibly related to the difficult word. Being a habit to Fatima, finding clues comes with ease.

Specifically, Jake and Fatima read again to find the hyphen and the clue turning point for metanoia. What they used is the strategy joining which allows comparing, classifying, and generalizing. In this case, Jake and Fatima generalized that turning point is related to metanoia perhaps because of the hyphen. In her statement, Ivy was certain that she learned the meaning of the 13 unknown words by re-reading and seeing the hints in the same sentence, thus underscoring the use of context clues found in the same sentence.

According to Anna, the use of VLS also requires rich vocabulary because words which may provide clues may also be unfamiliar to those with poor vocabulary. In such instance, a reader may not see the clue in other words anyway.

For captioning, Fatima saw syntax clue since other verbs appear with the word and applied the strategy joining. Since she saw captioning and uploading written with captioning, she classified all three as verbs and got a clue.

As to reason, Fatima stated that she thinks that using a dictionary is tiresome; that is why she resorts to context clues. To her surprise, she has learned so much from relying on context clues alone. Second, she is positive that authors deliberately provide clues. Depending on style and purpose, authors may be as giving. Scientific and technical texts may however come with limited clues since readers of such are assumed to be of the same field or knowledgeable about the topic and jargons.

The fact that the participants found clues is a good indicator of vocabulary knowledge. On the other hand, some readers cannot find clues at all; these readers then have troubles in reading [10].

Overall, participants referred to words in the same sentence. If they looked closely, they must have located the clues which are explicit in the same sentence among 21 of the highfalutin words. Generally, the author described the uncommon words using adjectives (e.g., absurdity, musings, and virtual), combined them with other words with parallel structure (e.g., curating), and provided examples (e.g., advocacy, flawed, and vanity).

Also, the paragraphs in which the word is written and even previous paragraphs provide insinuations leading to the meaning of the unfamiliar word. Other clues can be derived from the topic of a reading material, the goal of the reading material, and even the author of the reading material. These clues are however not as explicit as clues in the same sentence as the difficult words. In this pool, only Bessy read an entire paragraph to find hints. To her, an entire paragraph gives the context on how a word is used and what it possibly means. She applies this technique especially to words with multiple meanings. She is correct because the author of the text was generous in embedding the clues in paragraphs 1, 3, 4, 11 and 9 for the words fancy, tedious, junkies, and advocacy, respectively.

The reliance on context clues is also evident in the studies of Carranza, Manga, Dio, Jamora, and Romero [31]. Also, Schmitt [1] classified use of context clues as determination strategy. 
On the contrary, in the study of Christ, Chiu, Currie and Cipielewski [18], the kindergarten learners learned better the words presented without context. Although the words in the vocabulary test are without context, all participants asked for permission and read the article while answering the test. The re-reading was done to look for possible traces of word meaning among the words surrounding the unknown word.

Although often used, context clues have limitations $[5,28]$. Fatima acknowledged this limitation. According to her, "some words are just left alone $e^{6.13 "}$ or isolated. Isolated words offer no clue and no context at all.

\section{Using the dictionary}

Only Jake and Ervin did not mention the use of dictionary to know the meaning of unknown words. Although none of the respondents had a ready printed or digital downloaded dictionary on hand, the other four said the reference material is helpful to them. Looking for meaning by using dictionary is a determination strategy according to Schmitt [1].

The only brand mentioned by three participants-Ivy, Anna, and Fatima - was Merriam-Webster. In the grade 12 curriculum guide, monolingual Merriam Webster is mentioned along with English Oxford Dictionary. If teachers were faithful to the guide, they must have endorsed the same to their learners. Merriam-Webster Dictionary comes in printed and digital formats. While Ivy was interviewed at home and had her cellphone during this, she did not open it and later admitted that she does not have her own dictionary application in her phone. Bessy said she does not bring her printed dictionary all the time while Anna had no phone then because she just came from school during the interview.

Bessy likes printed dictionary which to Ivy is hard to use. The difficulty of using dictionary may root from not knowing the uninflected or base form of the word, its correct spelling, and correct alphabetical order, among others. Had Bessy used her printed dictionary, she might not have found the difficult words because they were in their inflected or derived form (e.g., deranged, flawed, scorched) in the text.

Ivy favors downloaded digital dictionaries. A digital dictionary contains meaning and other information or features which may not be presented in printed dictionaries.

Ivy later revealed that in class, students like her cannot openly use their phone with digital dictionary application. The teacher allows use of phone dictionaries only when she/he cannot provide meaning as requested by the students. Schools in the Philippines have policies prohibiting the bringing and use of phones as the latter prove to be distractive if they are not an instrument for cheating and gaming.

Fatima uses digital dictionaries for another reason. To her, these dictionaries are reliable and "updated". The internet is another source of new terms or neologies. This format also allows for more word entry therefore harboring the image of "near" completeness. Dynamism of language is one reason why no dictionary is complete.

Because of technology, post-millennials such as the interviewees can access word meanings more easily and have means to verify meaning by comparing available references. In this case, on the other hand, all respondents singled out Merriam-Webster despite the online availability of other dictionary brands.

The students' avoidance of using online dictionaries may also be because dictionaries offer definitions only in English, which may cause further confusion to the less advanced language learners.

Another challenge of using the dictionary is learning about words with multiple meanings. In the event participants referred to the dictionary, they may have to decide which of the multiple definitions apply. To define lavish and virtual, one needs to choose the second definition out of two given ones. Fancy, flawed, and subliminally are harder to define since the applicable meaning is only the third out of three or four choices. Deranged, junkies, musings, precipitated, and vanity are instantly defined by the dictionary but they come with alternative meanings too. The other unfamiliar terms come with a single definition.

This result, using the dictionary as VLS, affirms the studies of Haratmeh [3] and Choi [32]. In selecting the meaning of words, a reader must be mindful of how words are used. Definitions of idioms and figurative expressions are unavailable in a usual dictionary.

\section{Surfing the internet as the convenient choice}

Another strategy used by the participants is surfing the internet, particularly using Google as search engine. The researchers considered this as another theme since the participants singled out Google, not a particular dictionary, and since the dictionaries mentioned in the other theme were not internet-based or non-online. Schmitt [1] categorized this strategy as a determination strategy.

Although not restricted from using any reference material, all participants did not use any device to connect to the internet during and after reading the text. Also, none of the participants mentioned about the use of internet resources other than dictionary to improve their vocabulary. Other technology tools and games useful in developing vocabulary have been tried and proven effective in several studies [33-39].

There may be reasons why these tools are not fully explored. First is the cost of data or internet connection. The other issue is the speed and strength of such connectivity. Besides those, students may have priority searches or topics other than the ones related to vocabulary.

\section{Associating with familiar words and experiences}

Two interviewees named association as their VLS. 
Associating is a memory strategy [1] for it involves recollection of past experience with another word or a personal experience which is related to an unfamiliar word. Jake and Ervin mentioned association and identified various means to employ the technique.

For example, Jake associated the word subliminally with subtle. The two words are really connected since both connote that something is not obviously presented. As an aside, Jake mentioned that he had incidental exposure to the word subtle through interaction with others. He, on the other hand, mispronounced the word. Such exposure is meaningful for it makes one remember a word through association [30].

To know the meaning of metanoia, Jake once more used association. Association this time was with a synonymous word. Jake had a clue on the meaning of metanoia for having identified its synonym which is change. He particularly used Positive Network Theory or synonyms [14]. This strategy is possible only when prior knowledge on synonyms is intact. Change is not in the text, but Jake remembered it and allowed association perhaps because of turning point.

During the interview, Ervin used personal experience as point of association. Hence, schemata, regardless of source, count. The researchers verified if the association of metanoia was with the animated film RPG Metanoia, Ervin answered, "Yes. And I simply tried to associate it in the context of the sentence. It is like turning point, my metanoia point. I associated it as a significant event." At this point, he named associating as his top strategy but also relied on context clue using the word "turning". The association is with a life event, particularly a movie encountered in childhood.

Lastly, Ervin found the clues insights and long which are evident in social media to arrive at the meaning of musings. His exposure to blogging is also a way for him to acquire vocabulary. To the same word, he also associated sounds and structure of words; particularly, he related musings with amusing and muse. Sounds in homophones may, on the other hand, cause confusion. Hence, Ervin must be extra cautious on the use of this strategy. It is nice to know that even if prowess and captain are not related to musings, Ervin figured out insight which is very much related to reflection, the correct answer in the test.

Based on related literature, schema is salient to vocabulary improvement and reading [2] as it allows connections $[14,24]$. The connection to be made may range from a word heard or read, an experience whether good or bad, or anything under the sun which is part of a person's stock knowledge or memory. As in the case of Jake, the encounter with the word metanoia must have had impact on Ervin for him to remember it.

This result, using association as VLS, coincides with the conclusions of Larson, Rahn, Nippold, and Masterson [22] and of Nayena Blankson, O'Brien, Leerkes, Calkins, and Marcovitch [7]. The study of Choi [32] which was done locally also listed association as the preferred VLS of teachers and students. In Choi's, association is commonly done with personal experience.

\section{Analyzing word structure}

Jake and Ervin used analyzing word structure. For the word persona, Jake used structural analysis in a wrong way. He said that personal is the root word of persona; persona is actually derived from person. Jake answered persona correctly in the test.

Ervin also used structural analysis without his knowledge. He categorized this technique as a "different type of association". Specifically, he identified metanoia and musings as the only unfamiliar words but did not analyze them structurally. Metanoia has Greek etymology but no known root word while musings roots from musing (meaning meditation). Musing has inflectional affix which is "s," meaning plural. Other than plurality, the number of a noun may not be suggestive enough to tell meaning as in this case.

It is worth knowing that in some words (e.g., ballistic, candid, and vibe), this VLS may not work. These words are with only one morpheme or the smallest unit of a word with meaning. Hence, they cannot be broken down as to root word and affix. As for the words missed by Jake and Ervin, analyzing word structure may have yielded correct answers because curating and precipitated have root words and inflections while fancy has its root word and suffix.

This strategy is a favorite among Education student-participants [31].

\section{Asking "reliable" sources}

When possible, Ivy uses asking others as her VLS. Her reliable sources are her classmates who top the class. According to Ivy, one of her classmates is a good reference because of her intelligence. Ivy also said that vocabulary represents knowledge. The Aptitude Hypothesis of Anderson and Freebody assume that both vocabulary and comprehension reflect general intellectual ability. It states that the more intelligent a person is, the more words and the better comprehension she/he has. However, some experts simply relate vocabulary to comprehension $[10,23]$.

Ivy also asks her teachers about word meaning. Based on Ivy's statements, teachers include VLS in their instruction. They also make students check dictionary in the event they cannot tell the meaning of words. Occasions like this, therefore, give learners opportunity to practice their VLS. Teachers also promote the use of digital dictionaries as Ivy quoted her teacher for making her use the dictionary in her phone.

Generally, a student may have partial and shallow general vocabulary. Teachers may possess precise and even deep academic vocabulary. Both groups have 
receptive and productive vocabularies. Teachers know content vocabulary depending on their specialization or major [28].

More specifically, teachers may have core academic vocabulary that is content specific and specialized or jargon words while students have rich conversational vocabulary which is non-technical [23]. For example, the words absurdity, advocacy, aerial, ballistic, candid, curating, fancy, flawed, musings, precipitated, vanity, vibe, and virtual may be known to both teachers and students. Absurdity, advocacy, curating may be academic and familiar to teachers of Social Studies while precipitated in the lexicon, receptive and productive, of a Science teacher. Virtual and vibe may be part of the lexicon of a Computer teacher and a techie student. Ballistic, candid, fancy, flawed, musings, and vanity may be general and conversational terms to students and even to teachers ever-present in the online world.

Thus, social strategy such as asking someone for word meaning extends from seemingly knowledgeable classmates or contemporaries to teachers, all of whom are non-native speakers of English. A native speaker is usually the reliable reference in this social strategy.

This result contradicts the conclusion of Sarah Hsueh-Jui, Yu-Ju, and Cloudia Ya-Yu [34].

\section{Reading as habit}

Fatima was the only one who mentioned reading as a contributory factor to vocabulary knowledge or VLS. After the interview, she told the researchers that her father inspired her by modeling reading and collecting reading materials. Building of vocabulary is very much possible as one reads [4]. The amount of actual reading and the quality of materials make reading contributory to vocabulary knowledge $[2,5]$.

Based on asides, the researchers learned that Jake is into reading as well. He and Ervin love reading and writing for school paper. In fact, both entered the regional press conference. Jake competed in the editorial writing category while Ervin and his team placed third in radio broadcasting. In contrast, Ivy said jokingly that she does not read when not required and does not read long texts even when compelled to do so. Bessy and Anna read only academic and required texts.

Since the respondents were able to name their strategies, they were able to do metacognition. They thought about thinking and verbalized their strategies. Also, they have strategic competence or ability to repair problems in communication.

Overall, the participants think that the VLS they used in reading and use regularly are effective. Among those ranked, the most results-oriented are re-reading and analyzing structure for Jake, associating for Ervin, asking others for Ivy, and using context clues for Bessy, Anna and Fatima. On the other hand, Ivy used re-reading instead of asking during the reading and test taking.

The VLS also made them effectively identify correct word meaning. In analyzing the effectiveness of the top strategies, the researchers revisited the vocabulary test papers and checked if the participants answered correctly those words they named as unfamiliar during the interview. Jake identified subliminally as unfamiliar yet answered it correctly in the test thus getting 100\%. Ervin said he did not know metanoia and musings prior to reading but used association and got both (100\%) accurately in the test. Ivy answered five (advocacy, curating, persona, scorched, and subliminally) words correctly in the test or $38 \%$ of the 13 words which she thought she did not know. She applied re-reading. Anna answered deranged, junkies, musings, subliminally, and tedious or $80 \%$ of her perceived unknown words accurately. Lastly, Fatima answered metanoia correctly in the test but missed her other unfamiliar word curating, hence getting $50 \%$ effectiveness for using context clues.

The participants committed more errors compared with the number of unknown words they identified. Seemingly, they did not use the VLS in rechecking the meaning of words which they thought they knew. These words are absurdity, advocacy, aerial, ballistic, candid, curating, fancy, flawed, junkies, musings, precipitated, vanity, vibe, and virtual.

All of these words contain context clues, but Bessy missed four of these; Anna missed six; and Fatima missed four. Jake must have re-read the material and used structural analysis but did not answer curating, fancy, and precipitated though each word comes with a hint and can be broken down into root word and affix, either derivational (e.g., fancy) or inflectional (e.g., curating and precipitated). Meanwhile, Ervin could have associated absurdity with peak, curating with captioning and uploading, precipitated with tears and anger, and tedious with process if not with related personal experiences since he told the researcher that he likes posting pictures on Instagram and on Facebook. He was into blogging and video games as well before he got too busy in school.

Ivy had the most number of errors even if she said she read carefully the unknown words; she got lavish, aerial, metanoia, precipitated, deranged, and musings wrong. She declared all of these words as unfamiliar and perhaps re-read for word meaning.

These results imply the need to enhance the curriculum, particularly the instruction of vocabulary in senior high school, to improve vocabulary knowledge of learners, to give them realistic grasp of their vocabulary knowledge, to correct their erroneous notions such as that authors always provide clues to the meaning of highfalutin words and that using content clues is for the lazy, and to allow further learning and practice of VLS, more reading exposure, and more vocabulary-building experiences to occur.

\section{Conclusions}

The participants overestimated their vocabulary 
knowledge but used VLS. All these strategies are unique since learners apply them differently compared to how others use them. The VLS using context clues, analyzing word structure, and associating are part of the lessons in EAPP. They must have been given more attention that is why the participants use them. Meanwhile, re-reading connotes the lack of automaticity in terms of vocabulary knowledge. The fact that the same strategy is a pre-requisite to associating and finding clues also implies that it is not a stand-alone strategy. While asking is an acceptable strategy, the researchers think that it defeats the goal of VLS which is reading autonomy. It is then the hope of the researchers that the exposure to the word through the social strategy becomes a meaningful one that it could eventually prompt association and word learning. The results call for more reading practice for better vocabulary knowledge and application of VLS.

The paper acknowledges certain limitations such as snowball sampling and not testing the English proficiency of the respondents involved but recommends another sampling technique and testing of language proficiency to future researchers.

\section{REFERENCES}

[1] A. S. Bernardo. Developmental reading 1. Manila: Rex, 2009.

[2] D. Willingham, D. Price. Theory to Practice Vocabulary Instruction in Community College Developmental Education Reading Classes: What the Research Tells Us. Journal of College Reading and Learning. 40 (1), 91-105, 2009.

[3] M. S. Haratmeh. Involvement Load and Task Type In Task Effectiveness: Two Aspects Of Vocabulary Knowledge. International Journal of Academic Research, 4(4), 86-95. doi:10.7813/2075-4124.2012/4-4/B.13, 2012.

[4] K. J. Kindle. Using read-alouds to teach vocabulary. New York: Scholastic, 2011.

[5] B. D. Roe, B. D. Stoodt-Hill, P. C. Burns. Secondary school literacy instruction: The content areas $\left(10^{\text {th }} \mathrm{ed}.\right)$. Australia: Wadsworth, 2011.

[6] C. M. Sigmon. Systematic Word Study. New York: Scholastic, 2011.

[7] A. Nayena Blankson,, M. O'Brien, E. M. Leerkes, S. D. Calkins, S. Marcovitch. Do Hours Spent Viewing Television at Ages 3 and 4 Predict Vocabulary and Executive Functioning at Age 5?. Merrill-Palmer Quarterly, 61(2), 264-289, 2015.

[8] I. Cruz. English in Senior High. The Philippine Star, 26 March 2015

[9] B. A. Wasik, C. Iannone. Developing Vocabulary through Purposeful, Strategic Conversations. The Reading Teacher. 66 (4), 2013.
[10] J. P. Byrnes, B. A. Wasik, B. A. Language and literacy development. New York: Guilford Press, 2009.

[11] R. I. Lucas, E. Miraflores, D. Go. English Language Learning Anxiety among Foreign Language Learners in the Philippines. Philippine ESL Journal, vol. 7, 2011.

[12] R. J. Ebner, L. C. Ehri. Vocabulary Learning on the Internet: Using a Structured Think-Aloud Procedure. Journal of Adolescent \& Adult Literacy, 56(6), 480-489. doi:10.1002/JAAL.169, 2013.

[13] A. Thoermer, L. Williams. Using Digital Texts to Promote Fluent Reading. The Reading Teacher. 65 (7), April 2012.

[14] K. A. Mills, A. Levido. iPed: Pedagogy for Digital Text. The Reading Teacher. 65 (1), 2011.

[15] F. M. Al-Khasawneh. Vocabulary Learning Strategies: A Case of Jordan University of Science and Technology. English for Specific Purposes World. 12(34), 2012.

[16] D. T. Conley. 2007). The Prepared Graduate: The Challenge of College Readiness. Educational Leadership, Vol. 64(7), 2007

[17] C. Tumaliuan. Digital Realism. Philippine Daily Inquirer. Retrieved on June 19, 2017, from http://opinion.inquirer.net /96006/digital-realism, 28 July 2016.

[18] T. Christ, M. M. Chiu, A. Currie, J. Cipielewski. The Relation between Test Formats and Kindergarteners' Expressions of Vocabulary Knowledge. Reading Psychology, 35(6), 499-528. doi:10.1080/02702711.2012.7 46249, 2014.

[19] R. O. Hawkins, S. Musti-Rao, A. D. Hale, S. Mcguire, J. Hailley. Examining Listening Previewing as a Classwide Strategy to Promote Reading Comprehension and Vocabulary. Psychology in the Schools, 47(9), 903-916. doi:10.1002/pits.20513, 2010.

[20] H. F. Hsieh, S. E. Shannon. Three Approaches to Qualitative Content Analysis. Quality Health Research. 15(9). 1277-1288. doi:10.1177/1049732305276687, 2005.

[21] D. R. Thomas. A General Inductive Approach for Analyzing Qualitative Evaluation Data. American Journal of Evaluation. 27. 237-246. doi:10.1177/109821400528374 8, 2006.

[22] A. L. Larson, N. L., Rahn, M. Nippold, J. Masterson. Vocabulary Instruction on Sesame Street: A Content Analysis of the Word on the Street Initiative. Language, Speech \& Hearing Services in Schools, 46(3), 207-221. doi:10.1044/2015_LSHSS-14-0079, 2015.

[23] K. Flanigan, L. Hayes, S. Templeton, D. R. Bear, M. Invernizzi, F. Johnston, F. Words their way with struggling readers. Boston: Pearson, 2011.

[24] S. Wessels. Promoting Vocabulary Learning for English Learners. Reading Teacher, 65(1), 46-50. doi:10.1598/RT.6 5.1.6, 2011.

[25] S. L. Gillam, J. D. Fargo, K. C. Robertson. Comprehension of Expository Text: Insights Gained From Think-Aloud Data. American Journal of Speech-Language Pathology, 18(1), 82-94, 2009.

[26] E. K. Snell, A. H. Hindman, B. A. Wasik. How Can Book 
Reading Close the Word Gap? Five Key Practices from Research. Reading Teacher, 68(7), 560-571.doi:10.1002/trt r.1347, 2015.

[27] K. Yang. Structures of cognitive and metacognitive reading strategy use for reading comprehension of geometry proof. Educational Studies In Mathematics, 80(3), 307-326. doi:10.1007/s10649-011-9350-1, 2012.

[28] D. E. Alvermann, S. F. Phelps, V. G. Ridgeway. Content area reading and literacy: Succeeding in today's diverse classrooms ( $5^{\text {th }}$ ed.). Boston: Allyn and Bacon, 2007.

[29] J. P. Gipe. Multiple paths to literacy ( $7^{\text {th }}$ ed.). Boston: Pearson, 2010.

[30] K. O'Doherty, G. L. Troseth, P. M. Shimpi, E. Goldenberg, N. Akhtar, M. M. Saylor. (2011). Third-Party Social Interaction and Word Learning From Video. Child Development, 82(3), 902-915. doi:10.1111/j.1467-8624.20 11.01579.x, 2011.

[31] E. F. Carranza, A. A. Manga, R. V. Dio, M. J. Jamora, F. S. Romero, F. S. Vocabulary Learning and Strategies Used by Teacher Education Students. Asia Pacific Journal of Multidisciplinary Research, Vol. 3(2), 2015.

[32] S. E. Choi. Beliefs and preferences on vocabulary learning strategies of Korean students and their Filipino teachers. Unpublished Master's Thesis. Angeles City: Holy Angel University, 2013.

[33] J. Acha. The effectiveness of multimedia programmes in children's vocabulary learning. British Journal of
Educational Technology, 40(1), 23-31. doi:10.1111/j.14678535.2007.00800.x, 2009.

[34] L. Sarah Hsueh-Jui, L. Yu-Ju, H. Cloudia Ya-Yu. Exploring the Relationship between Self-Regulated Vocabulary Learning and Web-Based Collaboration. Journal of Educational Technology \& Society, 17(4), 404-419, 2014.

[35] Y. Fang-Chuan Ou, W. Wen-Chi Vivian. Using Mixed-Modality Learning Strategies via e-Learning for Second Language Vocabulary Acquisition. Journal of Educational Technology \& Society, 18(3), 309-322, 2015.

[36] S. J. Franciosi. The Effect of Computer Game-Based Learning on FL Vocabulary Transferability. Journal of Educational Technology \& Society, 20(1), 123-133, 2017.

[37] Y. Samur. Redundancy effect on retention of vocabulary words using multimedia presentation. British Journal of Educational Technology, 43(6), E166-E170. doi:10.1111/j. 1467-8535.2012.01320.x, 2012.

[38] W. Ting-Ting, H. Yueh-Min, H. Mobile Game-Based English Vocabulary Practice System Based on Portfolio Analysis. Journal of Educational Technology \& Society, 20(2), 265-277, 2017.

[39] L. Yu-Ju. The Effect of Technology-Supported Co-Sharing on L2 Vocabulary Strategy Development. Journal of Educational Technology \& Society, 16(4), 1-16, 2013.

[40] Z. Shen. The Effects of Vocabulary Knowledge and Dictionary Use on EFL Reading Performance. Canadian Center of Science and Education, 6(6), 77-85. 2013. 